\title{
Habitability of the early Earth: liquid water under a faint young Sun facilitated by strong tidal heating due to a closer Moon
}

\author{
René Heller $^{1,2}$ (D) Jan-Peter Duda ${ }^{3,4}$ (D) Max Winkler ${ }^{5} \cdot$ Joachim Reitner $^{4,6} \cdot$ Laurent Gizon $^{1,2,7}$
}

Received: 7 July 2020 / Accepted: 12 September 2021 / Published online: 24 November 2021

(C) The Author(s) 2021

\begin{abstract}
Geological evidence suggests liquid water near the Earth's surface as early as 4.4 gigayears ago when the faint young Sun only radiated about $70 \%$ of its modern power output. At this point, the Earth should have been a global snowball if it possessed atmospheric properties similar to those of the modern Earth. An extreme atmospheric greenhouse effect, an initially more massive Sun, release of heat acquired during the accretion process of protoplanetary material, and radioactivity of the early Earth material have been proposed as reservoirs or traps for heat. For now, the faint-young-Sun paradox persists as an important problem in our understanding of the origin of life on Earth. Here, we use the constant-phase-lag tidal theory to explore the possibility that the new-born Moon, which formed about 69 million years (Myr) after the ignition of the Sun, generated extreme tidal friction — and therefore, heat—in the Hadean and possibly the Archean Earth. We show that the Earth-Moon system has lost $\sim 3 \times 10^{31} \mathrm{~J}$ ( $99 \%$ of its initial mechanical energy budget) as tidal heat. Tidal heating of $\sim 10 \mathrm{~W} \mathrm{~m}^{-2}$ through the surface on a time scale of $100 \mathrm{Myr}$ could have accounted for a temperature increase of up to $5^{\circ} \mathrm{C}$ on the early Earth. This heating effect alone does not solve the faint-young-Sun paradox but it could have played a key role in combination with other effects. Future studies of the interplay of tidal heating, the evolution of the solar power output, and the atmospheric (greenhouse) effects on the early Earth could help in solving the faint-young-Sun paradox.
\end{abstract}

Keywords Early Earth $\cdot$ Tides $\cdot$ Moon $\cdot$ Faint-young-Sun paradox $\cdot$ Tidal brittle formation

Handling editor: Jörn Peckmann.

René Heller

heller@mps.mpg.de

Jan-Peter Duda

jan-peter.duda@geo.uni-tuebingen.de

Max Winkler

max.winkler@wwu.de

Joachim Reitner

jreitne@gwdg.de

Laurent Gizon

gizon@mps.mpg.de
Department of Geosciences, University of Tübingen, 72074 Tübingen, Germany

4 Göttingen Academy of Sciences and Humanities, 37073 Göttingen, Germany

5 Institut für Mineralogie, Universität Münster, Corrensstraße 24, 48149 Münster, Germany

6 Göttingen Centre of Geosciences, Georg-August-Universität Göttingen, 37077 Göttingen, Germany

7 Center for Space Science, NYUAD Institute, New York University Abu Dhabi, Abu Dhabi, UAE

1 Max Planck Institute for Solar System Research, Justus-von-Liebig-Weg 3, 37077 Göttingen, Germany

2 Institut für Astrophysik Göttingen, Georg-August-Universität Göttingen, Friedrich-Hund-Platz 1, 37077 Göttingen, Germany 
(a)

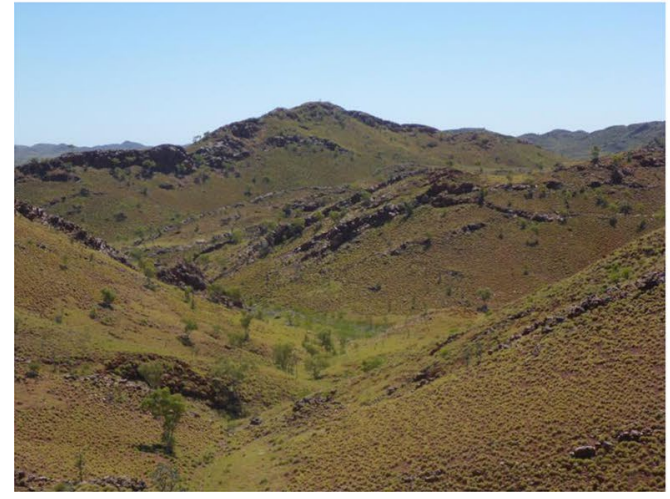

(b)

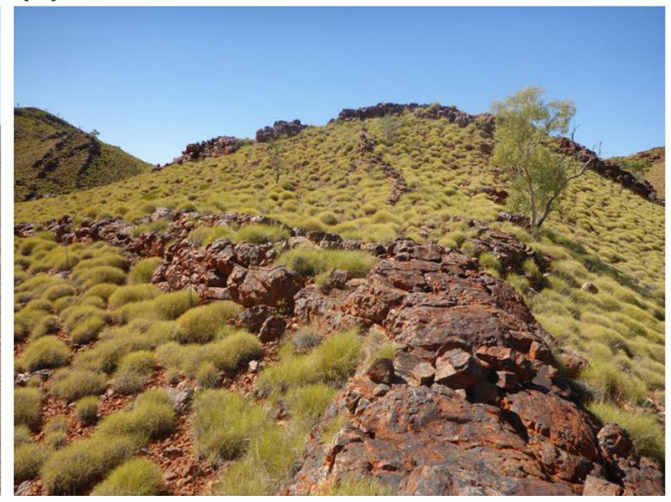

(c)

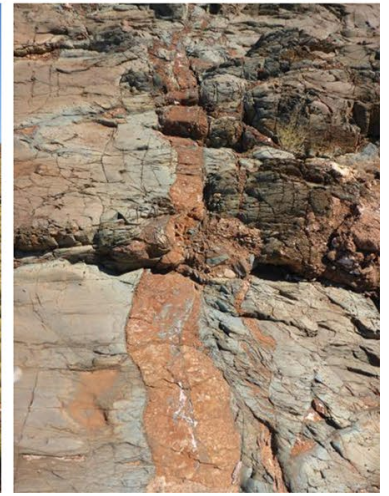

Fig. 1 a Early Archean basaltic rocks in the Pilbara region (Western Australia). These rocks evidently formed in aquatic environments as evidenced by pillow structures. Furthermore, pillow basaltic rocks such as the 3.49 Ga North Star Basalt are typically crosscut by numerous chert veins, which record intensive hydrothermal pumping of surface water through the crust at that time ("hydrothermal pump hypothesis"; Duda et al. 2018). b Detailed outcrop pattern of black chert veins. The vein in the front has a diameter of about 2-3 m. c Remarkably, these strata also show other types of evidence for brittle deformation such as widespread carbonate cemented fractures such as this 3.47 Ga Mount Ada Basalt. The brown color of the carbonate is characteristic for Fe-rich dolomites (ankerite). It appears plausible that such features are the product of strong tidal forces exerted by the much closer moon

\section{Introduction}

Geological records, such as oxygen isotope $\left(\delta^{18} \mathrm{O}\right)$ data from zircons, show that liquid water was present on the Earth's surface as early as 4.4 billion years ago (gigayears ago, $\mathrm{Ga})^{1}$ (Mojzsis et al. 2001; Wilde et al. 2001; Valley et al. 2014). This water would not have been pure water near room temperature and pressure but a high-temperature (300-450 K) and high-pressure ( $\sim 500$ bar) mix of $\mathrm{H}_{2} \mathrm{O}$ and $\mathrm{CO}_{2}$. Liu (2004) suggested that $\mathrm{CO}_{2}$ was then removed continuously over $\sim 100 \mathrm{Myr}$ to form carbonate rocks, although this is unfortunately not documented in the geological rock record. Life could have been present as early as $3.8-3.5 \mathrm{Ga}$ as suggested by possible biosignatures (particularly organic matter and its carbon isotopic composition) preserved in ancient rocks (Schidlowski 1988; Rosing 1999), and diverse aquatic life was certainly established by 3.5-3.4 Ga as for instance evidenced by organic biosignatures and fossil microbial mats (Lowe 1980; Walter et al. 1980; Allwood et al. 2006; Kranendonk 2011; Duda et al. 2016, 2018; Hickman-Lewis et al. 2018; Homann 2019). ${ }^{18} \mathrm{O} /{ }^{16} \mathrm{O}$ isotope ratios in marine

\footnotetext{
1 Throughout this manuscript, we use two time scales, one of which is typically used in astrophysics and one of which is often used in Earth sciences. The first one is the time after formation of the Sun, measured in units of millions of years (Myr) or billions of years (Gyr). The second one is the time before present, with units abbreviated as "Ga" for giga-annum (Arndt 2011). We use Ga for "gigayears ago" or "gigayears old". For the conversion between the time scales, we use a solar age of $4.567( \pm 0.06)$ Gyr determined from ${ }^{204} \mathrm{~Pb} /{ }^{206} \mathrm{~Pb}$ vs. ${ }^{207} \mathrm{~Pb} /{ }^{206} \mathrm{~Pb}$ isotope measurements in the Allende meteorite (Amelin and Krot 2007).
}

cherts and carbonates suggests Archean ocean temperatures between 50 and $85^{\circ} \mathrm{C}$ (Knauth 2005), although longevity and extent of these conditions remain unclear (see, e.g., discussion in Sengupta et al. 2020). Moreover, no evidence for glaciations exist until about $2.9 \mathrm{Ga}$ (von Brunn and Gold 1993; Young et al. 1998; van Kranendonk et al. 2012).

Early Archean basalts, such as the 3.49 Ga North Star Basalt in the Pilbara region (Western Australia) (Hickman 1977), typically exhibit pillow structures (Fig. 1). Since pillow structures form when hot, basaltic magma penetrates into a body of liquid water, they provide direct geological evidence for the presence of liquid surface water on the early Earth. ${ }^{2}$ The North Star Basalt and other Paleoarchean pillowed basalts in this area (e.g., Mount Ada Basalt, Apex Basalt, Euro Basalt) are typically crosscut by numerous chert veins, which record hydrothermal pumping of surface water through early Earths crust (Duda et al. 2018, "hydrothermal pump hypothesis").

As conclusive as the geological record is in regard to the presence of liquid water at (or near) the surface during the first billion years after the formation of the Earth, there is an astrophysical prediction that is in strong disagreement with these observations. Until about $3.5 \mathrm{Ga}$, the solar illumination on

\footnotetext{
${ }^{2}$ The formation of pillow basaltic rocks is a widespread phenomenon in today's oceans and been observed and documented at numerous locations (most famously on Hawaii, see, e.g., Grotzinger (2007), pp. 94-95, pp. 274-275). Importantly, this process is confined to subaquatic surface areas since it requires liquid water and space for the pillows to develop. For these reasons, we consider pillow basalts as robust geological indicators for the presence of liquid water in earlyEarth surface environments as well.
} 
Earth was only about $70 \%$ of its current value. With the solar radiation being the major energy source by far, simple energy balance calculations show that the reduction of the solar luminosity by $30 \%$ compared to its modern value should have led to a global snowball Earth for at least the first billion years or so (Sagan and Mullen 1972; Kasting et al. 1988).

One possibility to prevent global glaciation is through hugely enhanced atmospheric $\mathrm{CO}_{2}$ levels. Levels of 100-1000 times the present value have been shown theoretically to prevent a global snowball under a faint Sun 2.5 Gyr ago (Kuhn and Kasting 1983; Kasting 1987). This would correspond to $\mathrm{CO}_{2}$ partial pressures of between 0.03 and 0.3 bar, compared to $5 \times 10^{-4}$ bar today. Even more massive amounts of $\mathrm{CO}_{2}$ with up to between 10 and 100 bar of a $\mathrm{CO}_{2}$-CO dominated atmosphere have been suggested on the Hadean Earth (4.4-4 Ga) using model calculations (Nisbet and Sleep 2001). The lower end of this range overlaps with theoretical estimates of between 1 bar (Miller and Urey 1959) and 10 bar (Walker 1983) from atmosphere evolution models and with estimates for the $\mathrm{CO}_{2}$ inventory that could have been stored in the lithosphere (Sagan and Chyba 1997).

Alternatively, a 1 bar atmosphere with a $10^{-5}$ volume mixing ratio of $\mathrm{NH}_{3}$ could have generated the required magnitude of a strong greenhouse effect (Sagan and Mullen 1972). $\mathrm{NH}_{3}$, however, would be photodissociated through solar UV radiation on a time scale of just about 40 years (Kuhn and Atreya 1979) if it were not continuously supplied in adequate quantities by abiotic processes (Kasting 1982). Photodissociative destruction of $\mathrm{NH}_{3}$ could also have been prevented by an UV-opaque high-altitude haze composed of organic solids that were produced from $\mathrm{CH}_{4}$ photolysis (Sagan and Chyba 1997). Moreover, $\mathrm{CH}_{4}$ itself could have acted as an efficient greenhouse gas on the early Earth (Haqq-Misra et al. 2008). This argument, however, shifts the problem to the production of $\mathrm{CH}_{4}$. Where did it come from? If the only viable source of large amounts of $\mathrm{CH}_{4}$ is through methanogenic microorganisms (Pavlov et al. 2000; Kasting and Siefert 2002), then this is a chicken-and-egg dilemma: life would be required to create and maintain the conditions for it to have emerged in the first place.

Other explanations to solve the faint-young-Sun paradox include the assumption of a much more massive Sun $4.5 \mathrm{Ga}$ (Whitmire et al. 1995), a much lower fractional land coverage on Earth during the Archean (Flament et al. 2008), and different cloud distributions than today, all of which would affect the global albedo (Goldblatt and Zahnle 2011).

The atmospheric composition of the early Earth and the possibility of a greenhouse effect that is much stronger than the contemporary warming of $+33^{\circ} \mathrm{C}$ compared to an airless body (or of $+20.3^{\circ} \mathrm{C}$ compared to a gray atmosphere model, see "Energy balance in a gray atmosphere model") could certainly have played important roles in preventing a global snowball Earth. A specific interplay of various chemical, geothermal, and possibly biotic effects (at least once life was present) could solve the problem.

There is, however, a more apparent effect that has, to our perception, been underappreciated (Feulner 2012) or even overlooked (Charnay et al. 2020; Catling and Zahnle 2020) in the discussion of the faint-young-Sun paradox: that is, geothermal heating induced by the tidal deformation of the Earth by the newly formed Moon. In comparison to the other mechanisms detailed above, tidal heating always has a warming effect, whereas changes in the Earth's atmospheric composition, cloud coverage, land-to-surface fraction, albedo etc. could in principle also yield even lower temperatures in the absence of empirical model constraints. The energy budget difference between the initial and modern states of the Earth-Moon system provide firm constraints on the total amount of heat that must have been dissipated. Here, we present the basic calculations to address this tidal energy budget.

\section{Earth surface temperature}

\section{Sources of energy on the early Earth}

The surface temperature of the early Earth was determined by a balance between the energy flux provided by different energy sources and the energy loss through radiation as infrared emission into space. The most important energy sources were absorption of the solar radiation, the translation of the kinetic energy of accreted material (planetesimals) into heat, radiogenic decay of short-lived isotopes in the Earth's mantle and crust, and, to a smaller amount, conversion of gravitational energy into heat during chemical stratification.

The solar radiation varied substantially during the first 50 Myr after the formation of the Sun (see "Evolution of the solar luminosity"). After the Moon-forming impact some $69( \pm 10)$ Myr after the beginning of the solar system (Maltese and Mezger 2020); however, the solar flux settled at about $70 \%$ of its modern value and then increased at a rate of about $6 \%$ per billion years. The accretion of the Earth converted the gravitational energy of the incoming debris into heat on a time scale of 10-100 Myr, the total amount of which was comparable to the solar heat absorbed at the time (Turcotte and Pflugrath 1985). The most important short-lived radionuclides were ${ }^{26} \mathrm{Al}$ and ${ }^{60} \mathrm{Fe}$ (Urey 1955; Chaussidon and Gounelle 2007). Their short half-life times of 0.7 Myr and 1.5 Myr, respectively, made them important sources of energy for the first $10 \mathrm{Myr}$ or so, but negligible afterwards. The radiogenic decay of long-lived isotopes ${ }^{40} \mathrm{~K},{ }^{232} \mathrm{Th},{ }^{235} \mathrm{U}$, and ${ }^{238} \mathrm{U}$ provided about $0.2 \mathrm{~W} \mathrm{~m}^{-2}$ to the Hadean Earth (Spohn 1991; Gaidos et al. 2005). For comparison, the modern mean surface output of ${ }^{238} \mathrm{U}$ and ${ }^{232} \mathrm{Th}$ radioactive decay is $0.022_{-0.010}^{+0.015} \mathrm{~W} \mathrm{~m}^{-2}$ (Shimizu 2015) and 
the global mean heat flow is $0.092( \pm 0.004) \mathrm{W} / \mathrm{m}^{2}$ (Davies and Davies 2010). The residual heat is mostly due to cooling of the Earth from its accretion.

The Moon might have played another important role in the early Earth's energy budget. The key physical effect here is tidal heating, a phenomenon that is well known from observations of some of the rocky and icy moons of the solar system's giant planets. Io, the innermost of the four big moons of Jupiter, for example, is the volcanically most active body in the solar system (Smith et al. 1979) and its primary source of internal energy is tidal heating. As the heat generated by internal bodily friction comes at the expense of a loss of rotational and/or orbital energy, strictly speaking the source of the internal heat is actually external to the object that is heated (here: Io). Orbital perturbations from the other major satellites around Jupiter force Io on an eccentric orbit (Peale et al. 1979). Io's global mean tidal energy flux is about $2 \mathrm{~W} \mathrm{~m}^{-2}$ (Spencer et al. 2000). Another prominent example is Saturn's moon Enceladus, which shows tidally driven cryovolcanism (Porco et al. 2006). Similar to the case of Io, the reason for the ongoing tidal heating in Enceladus is its forced orbital eccentricity. The ultimate circularization of its orbit is inhibited by its gravitational interaction with another neighboring moon, in this case of Saturn's moon Dione (Meyer and Wisdom 2007).

Although detailed modeling of the tides in the Hadean Earth-Moon system cannot be found in the literature, the nearby Moon must have strongly deformed the Earth from its equilibrium shape. The fast rotation of the Earth compared to the orbital motion of the Moon led to a time lag (or a phase lag; Greenberg 2009; Efroimsky and Makarov 2013) between the line connecting the two centers of mass and the instantaneous orientation of the tidal bulge on Earth. This offset then led to friction inside the Earth, which triggered the tidal heating. Previous studies estimated that the contribution of tidal heating on the Earth's surface was $\lesssim 0.1 \mathrm{~W} \mathrm{~m}^{-2}$ about $100 \mathrm{Myr}$ after the Moon-forming impact, and therefore, irrelevant for the long-term global energy budget (Zahnle et al. 2007). These estimates were based on a specific tidal model (the constant phase lag tidal model) (Darwin 1879, 1880; MacDonald 1964; Ferraz-Mello et al. 2008) that implies a homogeneous composition of the Earth and a specific parameterization of the Earth's tidal dissipation, technically speaking the second-degree tidal Love number $\left(k_{2}\right)$ (Love 1909) and the tidal dissipation constant $(Q)$ (Goldreich and Soter 1966). Here, we show that the tidal heating rates in the early Earth might have been higher than previously thought.

\section{Energy balance in a gray atmosphere model}

We start our calculations by addressing the fact that the Earth's global mean effective surface temperature $\left(T_{\mathrm{s}}\right)$ is given by the thermal equilibrium between the absorbed incoming solar radiation and other internal energy sources on the one hand, and the emitted infrared radiation on the other hand. With $F_{\text {em }}$ as the emitted energy flux from Earth per unit surface area, we have (Stefan 1879; Boltzmann 1884; Planck 1901)

$T_{\mathrm{s}}=\left(\frac{F_{\mathrm{em}}}{\sigma_{\mathrm{SB}}}\right)^{1 / 4}$,

where $\sigma_{\mathrm{SB}}=5.670 \times 10^{-8} \mathrm{~W} \mathrm{~m}^{-2} \mathrm{~K}^{-4}$ is the Stefan-Boltzmann constant. In modern Earth, $F_{\text {em }}$ is dominated by the re-emission of the absorbed insolation,

$F_{\mathrm{em}}=\frac{L_{\odot}(t)}{4 \pi(1 \mathrm{AU})^{2}} \frac{(1-\alpha) \epsilon}{f}\left(1+\frac{3}{4} \tau\right)$,

where $L_{\odot}$ is the time-dependent solar luminosity ( $t$ is time), $\epsilon$ is the Earth's emissivity, ${ }^{3} \alpha$ is the Earth's Bond albedo, $f$ is an energy redistribution factor that accounts for the Earth's rotation, $\mathrm{AU}=150$ million $\mathrm{km}$ is the Sun-Earth distance, and $\tau$ is the atmospheric infrared gray opacity (Feulner 2012). In this equation, the Earth's atmosphere is assumed to be gray (Emden 1913), that is, its radiative properties are independent of wavelength $(\lambda)$. This approximation neglects the strong $\lambda$ variability of the solar flux reflection, absorption, and re-emission by the various atmospheric gaseous components, dust, and clouds (Sagan 1969; Wei et al. 2019). The term "gray" thus does not refer to the color of the atmosphere but to the non-dependence of the model on the wavelength.

For modern Earth, a typical parameterization of Eq. (2) uses $\alpha=0.3$ and $f=4$ (Selsis et al. 2007). Moreover, the gray opacity in the visible regime of the electromagnetic spectrum (called the optical depth) has been measured at the Earth's surface as $\tau \sim 0.35$ (Terez and Terez 2003). For now, we take this value as a proxy for $\tau$, which is assumed to be independent of wavelength, in the infrared but we rectify this assumption in "Combination of solar luminosity and tidal heating" and calibrate $\tau$ with the observed greenhouse warming. The Earth's emissivity can be approximated as $\epsilon=0.95$, between the values for water $(0.96)$ and limestone (0.92). For modern values of the solar luminosity, Eq. (2) yields $T=-6.3^{\circ} \mathrm{C}$. The deviation of $20.3{ }^{\circ} \mathrm{C}$ from the actual value of $+14^{\circ} \mathrm{C}$ is due to the well-known $\lambda$ dependence of

\footnotetext{
${ }^{3}$ Emissivity describes the ratio of the thermal radiation from a surface of a given temperature compared to the radiation from a black body surface at the same temperature.
} 
the atmospheric greenhouse effect-mostly due to $\mathrm{H}_{2} \mathrm{O}$, $\mathrm{CO}_{2}$, and $\mathrm{CH}_{4}$ - that is encapsulated in $\tau$. Obviously, the optical depth is not a good proxy for the infrared gray opacity and we return to this aspect in "Evolution of the solar luminosity" and Fig. 3. Nevertheless, Eq. (2) is a much better approximation than that of an airless Earth, which has a theoretical global mean equilibrium temperature of $-18^{\circ} \mathrm{C}$.

Early in the Earth's history, during as much as the first $1 \mathrm{Gyr}$ after formation, the solar luminosity was only about $70 \%$ of its current value, for which Eqs. (1) and (2) predict $T_{\mathrm{s}}=-29.1{ }^{\circ} \mathrm{C}$. Even additional heating from a greenhouse effect of about $+20.3^{\circ} \mathrm{C}$, as observed today, would be insufficient by far to prevent global freezing of the early Earth. More complex models that include both a warming greenhouse effect and an ice-albedo effect, which dramatically cools the planet as soon as it starts to have ice sheets, suggests that the Earth should have been even much cooler, raising the question of the yet unsolved early-faint-Sun or faint-young-Sun paradox (Sagan and Chyba 1997). That said, the composition of the early Earth atmosphere was entirely different from its modern counterpart and significant amounts of $\mathrm{CO}_{2}, \mathrm{CH}_{4}$, and $\mathrm{NH}_{3}$ could have further raised surface temperatures by several degrees Celsius. Nonetheless, atmospheric effects alone are unable to solve the faintyoung-Sun paradox (Kasting et al. 1988; Sagan and Chyba 1997).

In the following, we use theoretical models to investigate the possible role of tidal heating in the Hadean and Archean Earth due to the young, nearby Moon. We use sedimentological and geochemical evidence for the presence of liquid water as benchmarks (see "Introduction").

\section{Evolution of the solar luminosity}

Since the beginning, the energy budget of the Earth has been inherently liked with the luminosity of the Sun. The solar luminosity describes the electromagnetic energy output across all wavelengths and it currently amounts to $3.85 \times 10^{26} \mathrm{~W}$ (Chapman 1997) with decadal fluctuations of the order of $0.1 \%$ (Solanki et al. 2013). The solar luminosity cannot reliably be reconstructed even on a level of $1 \%$ for more than the past few decades. Hence, we resort to stellar evolution models to reconstruct $L_{\odot}(t)$ throughout the Earth's history.

Figure 2 shows a pre-computed stellar evolution model of a Sun-like star (Baraffe et al. 2015). The track illustrates the initial settling of the Sun on the main sequence, a phase which is dominated by radial shrinking and conversion of potential energy into heat. After about $20 \mathrm{Myr}$, the proton-proton nuclear reaction chain (Bethe 1939) kicks in, upon which the Sun almost doubles its energy output. After ongoing shrinking until about 40 Myr into the life of the Sun,

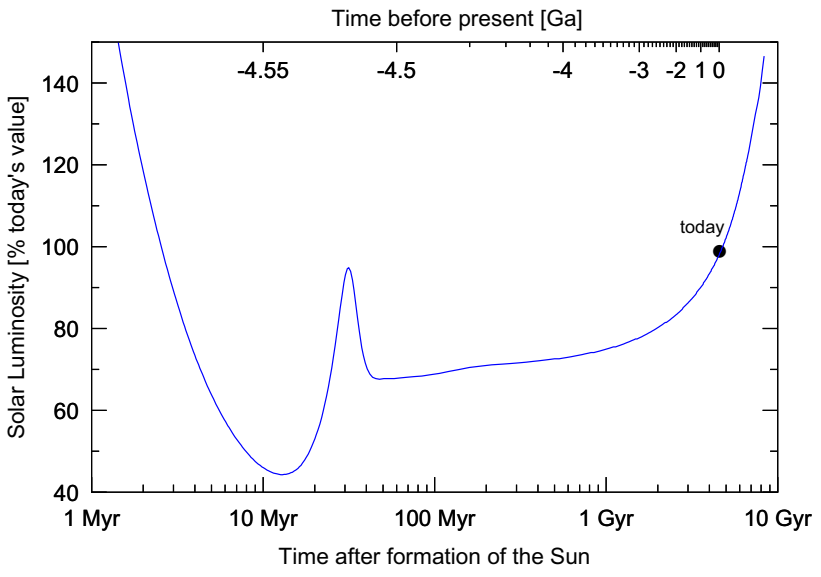

Fig. 2 Evolution of the solar luminosity as computed from a stellar evolution model (Baraffe et al. 2015). The age of the Sun of about $4.567 \mathrm{Gyr}$ is labeled with a black dot, at which time the model predicts a luminosity of $98 \%$ of the actual observed value. The abscissa at the bottom shows the modeled time after formation of the Sun-like star. The abscissa at the top shows the time before present in units of gigayears ago $(\mathrm{Ga})$

its luminosity settles at about $70 \%$ of its modern value and then increases at a rate of a little less than $1 \%$ per $100 \mathrm{Myr}$ for the next Gyr. At the current age of the Sun, marked by a black dot at $4.567 \mathrm{Gyr}$ along the bottom abscissa, the model predicts $98 \%$ of the actual value of the solar power output. In the following, we compensate for this offset by multiplying the stellar evolution model by a factor of 1.02 , which acts as a calibration to reproduce today's insolation. ${ }^{4}$

In Fig. 3, we illustrate the resulting evolution of the Earth's global mean effective surface temperature as per Eqs. (1) and (2). Different from Fig. 2, which uses a logarithmic scaling along the abscissa to highlight the strong luminosity variations of the young Sun, Fig. 3 uses a linear scaling. The blue-shaded area, present until $1.8 \mathrm{Gyr}$ after formation of the Sun ( $2.8 \mathrm{Ga}$ and before), marks the era of the early Earth, in which an additional heating of $+20.3^{\circ} \mathrm{C}$ by a modern Earth-like greenhouse effect cannot prevent the early Earth from becoming a global snowball. This time scale agrees with previous estimates (Sagan and Chyba 1997). The minimum temperatures achieved in this model are as low as nearly $-50^{\circ} \mathrm{C}$ before the Sun reaches an age of $50 \mathrm{Myr}$. In extreme scenarios, additional greenhouse warming from $\mathrm{CO}_{2}, \mathrm{CH}_{4}$, and $\mathrm{NH}_{3}$ could have prevented the

\footnotetext{
${ }^{4}$ Not shown in Fig. 2 is the variation of the solar spectral energy distribution, which might also have had a significant effect on the evolution of the Earth's atmospheric chemistry, and therefore, on the climate. To give just one example, the high-energy (short-wavelength, $\lambda<100 \mathrm{~nm})$ radiation of the early Sun ( $\sim 4 \mathrm{Ga}$ and before) was about 100-1000 times stronger than it is today (Ribas et al. 2005; Shapiro et al. 2020).
} 


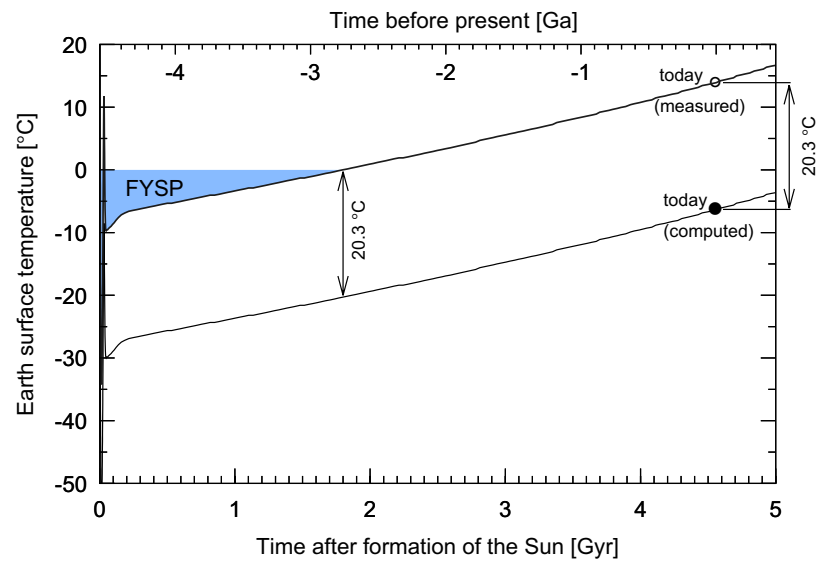

Fig. 3 Evolution of the early Earth's mean surface temperature under the assumption of a gray atmosphere, in which the wavelength dependence of the absorption of sunlight and re-emission in the infrared is neglected. The black thin line shows results as per Eqs. (1) and (2) with $\tau=0.35$ and using stellar evolution models (Baraffe et al. 2015). These models are multiplied by a factor of 1.02 to account for the offset between the predicted and the observed solar luminosity. The surface temperature computed for today is $-6.3^{\circ} \mathrm{C}$. The thick blue line shows a model forced to fit the measured value of $+14{ }^{\circ} \mathrm{C}$, for which $\tau=0.925$ is required. The blue-shaded area highlights the phase of sub-zero degree temperatures that cannot be explained by the additional heating of $+20.3^{\circ} \mathrm{C}$ from a greenhouse effect as on modern Earth. FYSP stands for faint-young-Sun paradox

late phase of the faint-young-Sun paradox near $2.2 \mathrm{Gyr}$ after formation of the Sun but not the first $700 \mathrm{Myr}$ (about $3.9 \mathrm{Ga}$ and before) with $T_{\mathrm{s}}$ as low as $-30^{\circ} \mathrm{C}$ as predicted by the gray atmosphere model. The black line in Fig. 3 is obtained using $\tau=0.925$, which raises temperatures by $20.3^{\circ} \mathrm{C}$ and reproduces the global mean surface temperature on the modern Earth.

\section{Tidal evolution}

\section{Mechanical energy loss through tides}

The effect of tidal heating - caused by the tidal forces from the young and nearby Moon, which probably formed as close as about 3.8 $R_{\oplus}$ (Canup 2004) following a giant impact $69( \pm 10)$ Myr after the beginning of the solar system (Maltese and Mezger 2020) —on the climate of the early Earth has hitherto not been studied in detail (but see Blackledge et al. 2020 for tidal simulations of the Earth-Moon system under possible Archean-like continental distributions). It has been suggested that tidal heating in the Earth has dropped below $100 \mathrm{~W} \mathrm{~m}^{-2}$ within a few Myr after the Moon-forming event and below $0.1 \mathrm{~W} \mathrm{~m}^{-2}$ within $100 \mathrm{Myr}$ (Zahnle et al. 2007). These estimates were based on parameterized models of tidal equilibrium theory with a fixed second order tidal Love number $\left(k_{2}\right)$ and constant tidal dissipation factor
$(Q)$ for the Earth. It is well known, however, that the tidal dissipation of viscous objects, such as the partly molten early Earth, is strongly dependent on the frequency of the tide-raising potential (Greenberg 2009), i.e., the Keplerian orbital frequency of the Moon in the reference frame rotating with the Earth. The feedback mechanism between the warming effect of tidal heating on the melt fraction of the early Earth's mantle and the resulting change of the efficiency of tidal heating, which have been studied for extrasolar Earthlike planets (Henning et al. 2009; Henning and Hurford 2014), have also not been studied in the young Earth-Moon system so far.

We do not consider these feedback mechanisms or the frequency dependence of the tidal $Q$ factor in this report either. Instead, our point is that previous calculations underestimated the effect of the enormous transfer of angular momentum from the fast-spinning early Earth to the orbit of the Moon (and the concomitant strong tidal heating) after the Moon-forming impact. In principle, this mechanism has been known for a long time, both from theory (Webb 1980, 1982) and from the interpretation of a banded iron formation in Australia (Walker and Zahnle 1986). Only recent advances in computer simulations of the actual impact scenario, however, suggested that the post-impact Earth had an extremely short rotation period, possibly near $2.2 \mathrm{~h}$ (Canup 2012), which is several times faster than previously assumed. As we demonstrate below, the resulting total amount of the dissipated tidal energy could have had a significant effect on the early Earth's energy budget.

To set the stage for our tidal heating calculations, we compute the total rotational and orbital energy in the Earth-Moon system directly after formation and today. Since the Earth-Moon system does not lose significant portions of its mechanical energy through other mechanisms than tidal dissipation, we can safely assume that the difference between the modern and early state of the system has been dissipated through tides almost exclusively inside the Earth. ${ }^{5}$ We assume that both the Earth and the Moon are solid, homogeneous spheres with masses of $M_{\oplus}=5.9736 \times 10^{24} \mathrm{~kg}$ and $M_{\varangle}=7.3477 \times 10^{22} \mathrm{~kg}$ and

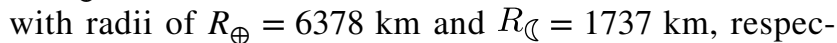
tively. Generally, the rotational energy of a solid sphere is $E_{\mathrm{rot}}=1 / 2 I \omega^{2}$, where $I=2 / 5 M R^{2}$ is the moment of inertia of a sphere with mass $M$ and radius $R$, and $\omega=v_{\text {rot }} / R$ is the angular velocity. The equatorial rotational speed $v_{\text {rot }}=2 \pi R / P_{\text {rot }}$ can be calculated using the rotational period $P_{\text {rot }}$. As a consequence,

\footnotetext{
5 Tides raised on the Earth by the Sun also contribute to the energy dissipation in the Earth's rotation, but solar tides were only on a percent level since the formation of the Earth-Moon system (Canup et al. 2001).
} 
$E_{\mathrm{rot}}=\frac{1}{5} M\left(\frac{2 \pi R}{P_{\mathrm{rot}}}\right)^{2}$

In addition to the rotational energy, there is (negative) orbital energy in the system, which is mostly stored in the orbital motion of the Moon and given as

$E_{\text {orb }, \varangle}=-\frac{1}{2} M_{৫}\left(\frac{2 \pi a}{P_{\text {orb }}}\right)^{2}$

where $a$ is the Moon's orbital semi-major axis on its Keplerian orbit around the Earth and

$$
P_{\text {orb }}=2 \pi \sqrt{a^{3} /\left(G\left(M_{\oplus}+M_{\zeta}\right)\right)}
$$

is its orbital period, as stated by Newton's derivation of Kepler's third law of motion (Kepler et al. 1619). For the initial post-impact state of the system we use $a^{\prime}=3.8 R_{\oplus}$, which gives $P_{\text {orb }}^{\prime}=10.4 \mathrm{~h} .{ }^{6}$ Today, $a=60.3 R_{\oplus}$ and $P_{\text {orb }}=27.32$ days. The total energy of the early Earth-Moon system and of the modern Earth-Moon system then is

$$
\begin{aligned}
E_{\text {tot }}^{\prime} & =E_{\text {rot, } \oplus}^{\prime}+E_{\text {rot, } \varangle}^{\prime}+E_{\text {orb }, \varangle}^{\prime} \\
& =3.06 \times 10^{31} \mathrm{~J}+1.27 \times 10^{27} \mathrm{~J}-6.17 \times 10^{29} \mathrm{~J} \\
& =3.00 \times 10^{31} \mathrm{~J}
\end{aligned}
$$

$$
\begin{aligned}
E_{\mathrm{tot}} & =E_{\mathrm{rot}, \oplus}+E_{\mathrm{rot}, \varangle}+E_{\mathrm{orb}, \varangle} \\
& =2.57 \times 10^{29} \mathrm{~J}+3.14 \times 10^{23} \mathrm{~J}-3.85 \times 10^{28} \mathrm{~J} \\
& =2.19 \times 10^{29} \mathrm{~J} .
\end{aligned}
$$

As a consequence, the change of the total energy in the system is $3 \times 10^{31} \mathrm{~J}-2.19 \times 10^{29} \mathrm{~J}=2.98 \times 10^{31} \mathrm{~J}$. In other words, the amount of mechanical energy stored in the modern Earth-Moon system is about $0.7 \%$ of the initial amount. 99.3\% of the initial amount of mechanical energy has been dissipated as heat through the Earth's surface in its $4.5 \mathrm{Gyr}$ history. This amount of energy is comparable to the modern solar energy output within one day.

\section{Tidal heating}

\section{Ad hoc tidal model}

The tidal evolution of the Earth-Moon system has initially been described in a rigorous mathematical framework by Darwin (1880), who developed an equilibrium tide model. This model assumes that the gravitational force of the tide raiser (here the Moon) elongates the perturbed body (here the Earth) and that this distortion is slightly misaligned to

\footnotetext{
${ }^{6}$ Here and in the following, quantities referring to the early EarthMoon system are labeled with a prime $\left(^{\prime}\right)$.
}

the line connecting the two centers of mass. This misalignment is due to dissipative processes within the deformed body, that is, currently mostly in the Earth's oceans, and it leads to a secular evolution of the orbit and spin angular momenta (Zschau 1978).

The resulting transfer of angular momentum, mostly between the Earth's rotation and the orbit of the Moon, leads to an increase of $a$ and, hence, to a decrease of $\dot{E}^{\prime}{ }_{\text {tid }}$ on a time scale of 10-100 Myr, the details of which are in fact unknown. Detailed modeling of the tidal heating evolution in the early Earth would require a better knowledge of the planetary structure, in particular of the thickness and temperature of a possible mantle in which most of the tidal heating is supposed to occur (Henning et al. 2009). Our knowledge of the internal evolution of the early Earth after the Moonforming giant impact, however, is far from being complete. In fact, these uncertainties in the parameterization of the model would dominate the (unknown and so far untestable) errors in the results of a detailed modeling of the orbital evolution in the early Earth-Moon system.

Because of these uncertainties, we start our reflections on the tidal heating with a simple but not necessarily implausible approach and characterize the evolution of the tidal heating rate by a characteristic tidal heat flux $\left(F_{\mathrm{t}, 0}\right)$ and a characteristic time scale for the tidal evolution $\left(t_{\text {tid }}\right)$. Orbital evolution due to tides as well as the resulting tidal heating often follow an exponential or near-exponential decay law (Zahnle et al. 2007). We, therefore, parameterize the evolution of the tidal heat flux as

$F_{\mathrm{t}}(t)=F_{\mathrm{t}, 0} e^{-t / t_{\mathrm{tid}}}$

As a boundary condition for Eq. (7), the tidal surface heat flux integrated age of the Earth $(T)$ and multiplied by the surface of the Earth must be equal to the difference between the amounts of mechanical energy in the early and modern Earth-Moon systems (Eqs. 5-6),

$4 \pi R_{\oplus}^{2} \int_{0}^{T} \mathrm{~d} t F_{\mathrm{t}}(t)=E_{\mathrm{tot}}^{\prime}-E_{\mathrm{tot}}=2.98 \times 10^{31} \mathrm{~J}$.

\section{Constant-phase-lag model}

The constant-phase-lag (CPL) model assumes that the phase (or angle) lag between the Earth's equilibrium tidal bulge and the line connecting the Earth-Moon barycenters is constant during the orbit (Ferraz-Mello et al. 2008; Greenberg 2009; Heller et al. 2011; Efroimsky and Makarov 2013).

In the absence of significant eccentricity or obliquity, Barnes (2017) finds that $Q_{\oplus}=34.5$ results in an orbital evolution that places the Moon at the Earth's surface 4.5 Ga. A similar approach by Zahnle et al. (2015) predicts 
$Q_{\oplus} \sim 30$. Although the Moon did not form at the Earth's surface but instead near the Earth's Roche radius, beyond which tidal forces were too weak to prevent accretion of the Moon, Zahnle et al. (2015) show that this proxy results in initial tidal heating rates near $100 \mathrm{~W} \mathrm{~m}^{-2}$, at least for the first few million years post-impact. For comparison, threedimensional simulations of tidal dissipation in the early Earth oceans suggest that $Q_{\oplus} \sim 1$ might, under certain circumstances, be plausible (Blackledge et al. 2020). For our nominal parameterization of the CPL model, we chose $Q_{\oplus}=12$ as in modern Earth. ${ }^{7}$

The rate of the tidal energy dissipation is calculated as the sum of the loss of orbital energy and rotational energy. To calculate the tidal energy dissipation in the early Earth as a function of time, we use the formulation of the CPL model by Heller et al. (2011). Their set of differential equations for $\mathrm{d} a / \mathrm{d} t, \mathrm{~d} e / \mathrm{d} t$, $\mathrm{d} \omega / \mathrm{d} t$, and $\mathrm{d} \psi / \mathrm{d} t$ ( $\psi$ being the obliquity or angle between the spin normal and the orbital plane) allows us to calculate the spin-orbit evolution. We also use their equations for the change of the orbital energy $\left(\dot{E}_{\mathrm{orb}, i}\right)$, where

$$
i \in\{\oplus, \diamond\}
$$

, and for the change of the rotational energy $\left(\dot{E}_{\mathrm{rot}, j}\right)$. The total energy released inside the Earth and the Moon then is

$\dot{E}_{\mathrm{tid}, i}=-\left(\dot{E}_{\mathrm{orb}, i}+\dot{E}_{\mathrm{rot}, i}\right)>0$,

respectively, and the globally averaged mean flux of the tidal heating is

$h_{\mathrm{tid}, i}=\frac{\dot{E}_{\mathrm{tid}, i}}{4 \pi R_{i}^{2}}$.

\section{Comparison of tidal models}

In Fig. 4, we show the tidal heat flux in the early Earth for three different choices of $t_{\text {tid }}$ and $F_{\mathrm{t}, 0}$ in Eq. (7) that satisfy the energy loss criterium of Eq. (8) (dashed lines). All three choices are compared to the absorbed electromagnetic energy flux from the Sun as per Eqs. (1) and (2) and using pre-computed stellar evolution models (Baraffe et al. 2015) (black solid line). We find that even the most extreme

\footnotetext{
${ }^{7}$ We also investigated alternative choices of $Q_{\oplus}$. Interestingly, whatever reasonable value we chose $(1.2,12,120)$ the resulting track of the tidal heating rates remained almost unchanged. The reason for this is in the concomitant change of the rate of the orbital evolution: if $Q_{\oplus}$ is increased (decreased), the rate of the orbital expansion decreases (increases). As a result, for any point in time, the tidal heating would be higher (lower) due to the change in $Q_{\oplus}$, but this change is almost precisely counterbalance by the variation of the orbital semi-major axis. In fact, tidal heating changes only by a factor of a few even if we change $Q_{\oplus}$ by an order of magnitude.
}

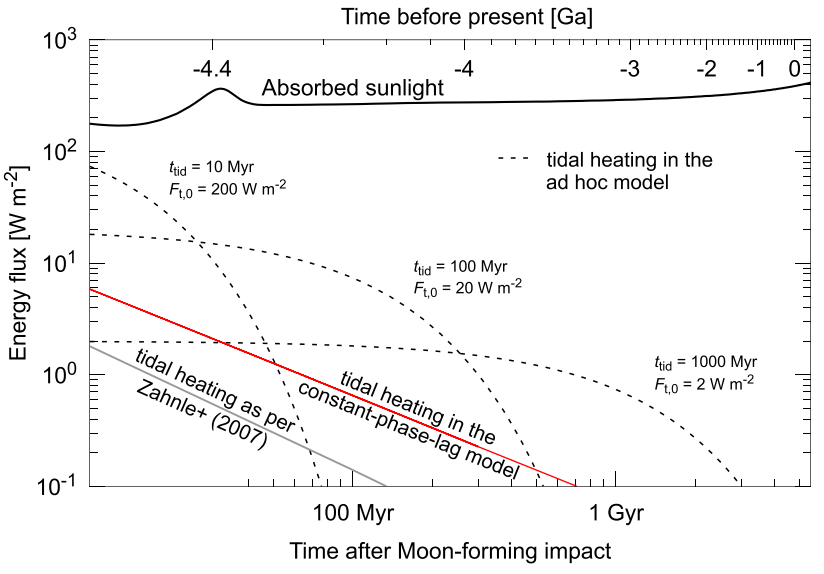

Fig. 4 Calculated tidal heat flux in the early Earth compared to the absorbed radiation from the young Sun (black solid line). Three different choices for the parameterization of the ad hoc model in Eq. (7) result in the example tidal heat fluxes as labeled along the tracks (dashed lines). The evolution of the tidal heating rate as per the CPL model (red solid line) is based on numerical integrations of the orbital evolution of the early Earth-Moon system. Tidal heating rates from Zahnle et al. (2007) are shown for comparison (gray solid line)

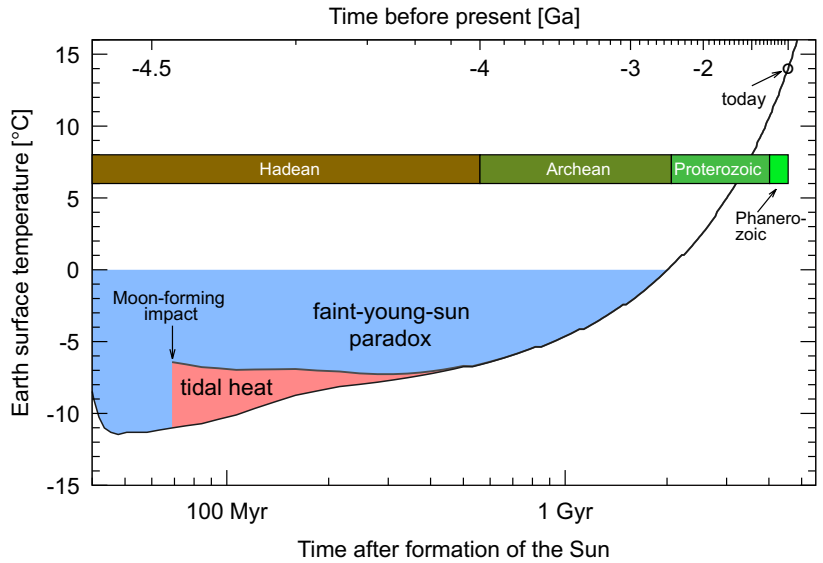

Fig. 5 Evolution of the early Earth's mean surface temperature using energy input from both insolation and tidal heat flux. The gray opacity of the Earth atmosphere is set to $\tau=0.925$ to force the atmosphere model to reproduce modern Earth temperatures. The blue line shows results as per Eqs. (1) and (2) and using stellar evolution models (Baraffe et al. 2015) calibrated to reproduce the modern power output of the Sun. The blue-shaded area highlights the phase of sub-zero temperatures. The red shaded area, the integral of which contains $2.98 \times 10^{31} \mathrm{~J}$ as per Eq. (8), illustrates an increase of the temperature due to tidal heating assuming $F_{\mathrm{t}, 0}=20 \mathrm{~W} \mathrm{~m}^{-2}$ and $t_{\mathrm{tid}}=100 \mathrm{Myr}$ in Eq. (7). Geological ages are highlighted with horizontal bars. In summary, tidal heating alone cannot possibly solve the faint-young-Sun paradox. Nevertheless, it could have been an important $\left(>1{ }^{\circ} \mathrm{C}\right)$ compensation of the low solar luminosity in the first $\sim 220 \mathrm{Myr}$ (before about $4.35 \mathrm{Ga}$ ) to prevent a global snowball Earth

parameterization of the tidal heat flux with $t_{\text {tid }}=10 \mathrm{Myr}$ and $F_{\mathrm{t}, 0}=200 \mathrm{~W} \mathrm{~m}^{-2}$ can barely compete with the solar absorbed flux on a time scale of $10 \mathrm{Myr}$, a time which would 
be measured after the Moon-forming impact. A more moderate and more reasonable choice of $t_{\text {tid }}=100 \mathrm{Myr}$ and $F_{\mathrm{t}, 0}=20 \mathrm{~W} \mathrm{~m}^{-2}$ results in about $10 \mathrm{~W} \mathrm{~m}^{-2}$ of tidal surface heating for the first $\sim 100 \mathrm{Myr}$ after formation of the Earth, and therefore, could have been a significant source of energy during its early lifetime. This parameterization is used again as a reference tidal heat flux in Fig. 5. The resulting decay of tidal heating is in agreement with previous estimates (Feulner 2012) of $\sim 0.02 \mathrm{~W} \mathrm{~m}^{-2}$ during the Archean (4-2.5 Ga). An even more moderate parameterization using $t_{\text {tid }}=1000 \mathrm{Myr}$ and $F_{\mathrm{t}, 0}=2 \mathrm{~W} \mathrm{~m}^{-2}$ would keep tidal heating about two orders of magnitude smaller than the amount of absorbed sunlight.

We also compare the ad hoc tidal model to the tidal heating rates computed via numerical integration of the differential equations for the CPL model (red solid line). The shape of the curve of $h_{\mathrm{tid}, i}(t)$ in the CPL model is remarkably different from the shape of the track in the ad hoc model. Any parameterization of the ad hoc model that we examine predicts stronger initial tidal heating than the CPL model. In turn, the CPL model provides more tidal heating in the long term, with over $1 \mathrm{~W} \mathrm{~m}^{-2}$ during the first $70 \mathrm{Myr}$ and up to $0.1 \mathrm{~W} \mathrm{~m}^{-2}$ during the first $700 \mathrm{Myr}$. We have validated that the total energy dissipated through the Earth's surface is the same in all cases of the ad hoc model and the CPL model. Previously postulated tidal heating rates (Zahnle et al. 2007) are a factor of three to five smaller than the values that we compute using the CPL model. This is likely due to different initial conditions (in particular the rotation rate of the post-impact Earth) and different $Q_{\oplus}$ values.

Although all these tidal models produce tidal heat fluxes that are small compared to the solar energy input, even a conservative value of $F_{\mathrm{t}, 0}=2 \mathrm{~W} \mathrm{~m}^{-2}$ is comparable to the global mean flux from tidal heating observed on Jupiter's volcanically active moon Io (Spencer et al. 2000). It has been argued that this level of a surface heating through an internal heat source could trigger global volcanism on Earth-sized planets as well (Barnes et al. 2009). If this were the case, then even our most conservative choice of the parameterization of the evolution of tidal heating could have resulted in extreme geophysical processes on the early Earth that could possibly have produced strongly enhanced $\mathrm{CO}_{2}$ outgassing and a substantial, long lasting greenhouse effect. In other words, beyond the direct heating effect of tidal friction, tides could have triggered further geophysical activities, whichas a secondary effect-could have heated the early Earth. Beyond that, the rapid resurfacing could have precluded the development of a biosphere (Barnes et al. 2009).

The comparison with the global mean internal heat emission of $2 \mathrm{~W} \mathrm{~m}^{-2}$ from the surface of the volcanically active Io introduces another interesting possibility. The widespread occurrence of ultramafic rocks such as komatiites before $3 \mathrm{Ga}$ has been interpreted as evidence for a higher geothermal gradient in the early Earth (Nesbitt et al. 1982; Herzberg et al. 2010). A detailed study of the convective heat and matter transport in the early Earth's mantle and crust are beyond the scope of this article. However, our results demonstrate the potential of tidal heating as a mechanism to explain, at least partly, the observations of two phenomena, that is, the faint-young-Sun paradox and the enhanced internal heat flow in the Archean.

On the more speculative side, the tidal forces acting on the crust of the Archean Earth might have left scars in the geological record. The thousands of black chert veins of the Dresser Formation (North Pole region, Western Australia; see Fig 1a, b) formed in a volcanic caldera system (Kranendonk et al. 2008) document intensive brittle deformation of the crust $3.49 \mathrm{Ga}$ ago. In the light of our findings, it is tempting to hypothesize that the obvious mechanical disruption of the crust was at least in parts caused by strong tidal forces imparted by the nearby early Moon. This would also be in good accordance with abundant carbonate-filled fractures as, e.g., observed in the 3.47-Gyr-old Mt. Ada Basalt (see Fig 1c). Taken together, significantly higher tidal forces due to the much closer early Moon plausibly resulted in brittle deformation of the crust and enhanced geothermal activity in the Archean Earth.

\section{Combination of solar luminosity and tidal heating}

Equipped with Eq. (2) for the globally averaged insolation absorbed by the Earth, a pre-computed track of the solar luminosity to feed into Eq. (2), and an evolutionary model for the Earth's tidal heat flux as per Eq. (7), we can now set $F_{\text {em }}=F_{\odot}+F_{\mathrm{t}}$ in Eq. (1) and re-evaluate the evolution of the Earth's global mean surface temperature.

We calibrate Eq. (2) to reproduce the modern Earth value of $T_{\mathrm{s}}=+14{ }^{\circ} \mathrm{C}$ by setting the infrared gray opacity to $\tau=0.925$. This approach can be seen as forcing the gray atmosphere model to encapsulate all the complex radiative properties of the Earth's atmospheric gases in the free parameter $\tau$. We also choose $F_{\mathrm{t}, 0}=20 \mathrm{~W} \mathrm{~m}^{-2}$ and $t_{\text {tid }}=100 \mathrm{Myr}$ in Eq. (7), a parameterization that gives a total amount of dissipated tidal energy through the Earth's surface that is compatible with the observations from orbital mechanics (Eqs. 5-6).

In Fig. 5, we plot $T_{\mathrm{s}}(t)$ for this parameterization of the model. The blue line at the bottom refers to the gray atmosphere model (forced to reproduce modern Earth surface temperatures) without the additional contribution of tidal heating. The minimum temperatures reached in this model are $-11.5^{\circ} \mathrm{C}$ at $50 \mathrm{Myr}$ after formation of the Sun.

The red line in Fig. 5 refers to Earth's mean surface temperature based on the sum of the tidal plus solar absorbed flux on Earth. The contribution from tidal heating on the early Earth's surface temperature is highlighted by the red 
shaded area. In this model, the Moon-forming impact (set to $69 \mathrm{Myr}$ after the formation of the Sun; Maltese and Mezger 2020) results in an addition of tidal heat flux, which keeps temperatures near $-7{ }^{\circ} \mathrm{C}$ instead of the $-11.5^{\circ} \mathrm{C}$ mentioned above. In the following, the tidal heat flux decreases while the solar luminosity increases by comparable fraction. As a consequence, the Earth's surface temperature remains almost constant near $-7^{\circ} \mathrm{C}$. After this phase, tidal heating vanishes, whereas the solar luminosity continues to climb. The temperature offset triggered by tidal heating is up to about $+5{ }^{\circ} \mathrm{C}$ within the first $10 \mathrm{Myr}$ after the Moon-forming impact and $>1{ }^{\circ} \mathrm{C}$ for the first $\sim 150 \mathrm{Myr}$ of the newly formed Earth-Moon system. Assuming a Moon-forming impact 69 Myr after formation of the Sun, our results imply that tidal heating could have been significant for the maintenance of liquid surface water up until $220 \mathrm{Myr}$ after the formation of the Sun, that is, until about $4.35 \mathrm{Ga}$ (see Fig. 5). The periods of the Hadean (4.56-4 Ga), Archean (4-2.5 Ga), Proterozoic (2.5-541 Ma), and Phanerozoic (541 Ma-today) geological ages are also shown in Fig. 5. This comparison shows that tidal heating in the Earth due to the nearby Moon was only relevant in the Hadean, at least for this choice of a parameterization of our model.

We have also explored other reasonable parameterizations of Eq. (7) and found that, in no case, tidal heating alone could contribute the required amount of heat to bypass the faint-young-Sun paradox and prevent a global snowball Earth. Either tidal heating is short $\left(t_{\text {tid }} \lesssim 10 \mathrm{Myr}\right)$ and extreme $\left(F_{\mathrm{t}, 0} \sim 200 \mathrm{~W} \mathrm{~m}^{-2}\right)$, in which case it is sufficiently strong to push the global mean temperature of the early Earth above $0{ }^{\circ} \mathrm{C}$ - but only for a few $\mathrm{Myr}$, and therefore, much too short. Or tidal heating acts on a longer time scale $\left(t_{\text {tid }} \gtrsim 100 \mathrm{Myr}\right)$ and with a more moderate magnitude $\left(F_{\mathrm{t}, 0} \sim 20 \mathrm{~W} \mathrm{~m}^{-2}\right)$, but then it never lifts $T_{\mathrm{s}}$ above $0{ }^{\circ} \mathrm{C}$.

Irrespective of the details of the actual evolution of tidal heating, the overall dissipation of the mechanical energy budget ("Tidal heating") suggests that this mechanism was not negligible in the early Earth. On the contrary, we demonstrate that tidal heating factored significantly into the heat budget of early Earth, likely contributing to the prevention of a global snowball state.

\section{Conclusions}

We have shown that the modern Earth-Moon system only contains about $1 \%$ of its initial spin-orbit energy budget, when the Earth was a fast rotator and the Moon was in an extremely tight orbit. Most of the energy has been dissipated through tides, and we show that the resulting tidal heating may have had a much larger effect on the Earth's mean surface temperature than previously thought. Our combination of a gray atmosphere model with an ad hoc model for the evolution of the Earth's tidal heating rate, which is compatible with the total energy released in the Earth-Moon system, predicts that tidal heating may have contributed a heating of several degrees Celsius within the first $100 \mathrm{Myr}$ of the life of the Earth.

Although tidal heating in the Earth from a closer Moon cannot possibly solve the faint-young-Sun paradox alone, our results suggest that it could have played an important role in maintaining liquid water at the surface. As a bonus, tidal heating as a geothermal heat source might have helped to sustain enhanced mantle temperatures, for instance by driving hydrothermal fluid circulation in early Earth's crust. This interpretation would be compatible with the previously stated "hydrothermal pump" concept, which asks for an internal heat source and strong forces in the crust of the Archean Earth to explain the presence of 3.49-Gyr-old black chert veins of the Dresser Formation (Western Australia). A unified model that includes geophysical, atmospheric, tidal, and astrophysical effects could be able to resolve the longstanding faint-young-Sun paradox.

Acknowledgements The authors are thankful to Rory Barnes and an anonymous referee for their helpful comments on the manuscript.

Funding Open Access funding enabled and organized by Projekt DEAL. RH and LG acknowledge support from the German Aerospace Center (Deutsches Zentrum für Luft- und Raumfahrt) under PLATO Data Center Grant 50OO1501. JPD and JR acknowledge support from the DFG SPP 1833 "Building a Habitable Earth" (DU 1450/3-1, DU 1450/3-2, and RE 665/42-2).

Availability of data and material Not applicable.

\section{Declarations}

Conflict of interest The authors declare that they have no conflict of interest.

Code availability The gnuplot scripts used to plot Figs. 2, 3, 4 and 5 can be requested via e-mail from the author RH (heller@mps.mpg.de).

Open Access This article is licensed under a Creative Commons Attribution 4.0 International License, which permits use, sharing, adaptation, distribution and reproduction in any medium or format, as long as you give appropriate credit to the original author(s) and the source, provide a link to the Creative Commons licence, and indicate if changes were made. The images or other third party material in this article are included in the article's Creative Commons licence, unless indicated otherwise in a credit line to the material. If material is not included in the article's Creative Commons licence and your intended use is not permitted by statutory regulation or exceeds the permitted use, you will need to obtain permission directly from the copyright holder. To view a copy of this licence, visit http://creativecommons.org/licenses/by/4.0/. 


\section{References}

Allwood, A.C., M.R. Walter, B.S. Kamber, C.P. Marshall, and I.W. Burch. 2006. Stromatolite reef from the early archaean era of Australia. Nature 441(7094): 714-718. https://doi.org/10.1038/ nature04764.

Amelin, Y., and A. Krot. 2007. Pb isotopic age of the Allende chondrules. Meteoritics \& Planetary Science 42(7-8): 1321-1335. https://doi.org/10.1111/j.1945-5100.2007.tb00577.x.

Arndt, N. 2011. Ga, 621-621. Berlin: Springer. https://doi.org/10.1007/ 978-3-642-11274-4_611.

Baraffe, I., D. Homeier, F. Allard, and G. Chabrier. 2015. New evolutionary models for pre-main sequence and main sequence low-mass stars down to the hydrogen-burning limit. Astronomy \& Astrophysics 577: A42. https://doi.org/10.1051/0004-6361/ 201425481.

Barnes, R. 2017. Tidal locking of habitable exoplanets. Celestial Mechanics and Dynamical Astronomy 129(4): 509-536. https:// doi.org/10.1007/s10569-017-9783-7. arXiv:1708.02981.

Barnes, R., B. Jackson, R. Greenberg, and S.N. Raymond. 2009. Tidal Limits to Planetary Habitability. The Astrophysical Journal Letters 700(1): L30-L33. https://doi.org/10.1088/0004-637X/700/1/ L30.

Bethe, H.A. 1939. Energy production in stars. Physical Review 55: 434-456. https://doi.org/10.1103/PhysRev.55.434.

Blackledge, B.W., J.A.M. Green, R. Barnes, and M.J. Way. 2020. Tides on Other Earths: Implications for Exoplanet and PalaeoTidal Simulations. Geophysical Research Letters 47(12): e85746. https://doi.org/10.1029/2019GL085746.

Boltzmann, L. 1884. Ableitung des Stefan'schen Gesetzes, betreffend die Abhängigkeit der Wärmestrahlung von der Temperatur aus der electromagnetischen Lichttheorie. Annalen der Physik 258(6): 291-294. https://doi.org/10.1002/andp.18842580616.

Brunn, V. von, and D. Gold. 1993. Diamictite in the Archaean Pongola sequence of Southern Africa. Journal of African Earth Sciences (and the Middle East) 16(3): 367-374. https://doi.org/10.1016/ 0899-5362(93)90056-V.

Canup, R.M. 2004. Simulations of a late lunar-forming impact. Icarus 168(2): 433-456. https://doi.org/10.1016/j.icarus.2003.09.028.

Canup, R.M. 2012. Forming a moon with an earth-like composition via a giant impact. Science 338(6110): 1052-1055. https://doi.org/10. 1126/science.1226073.

Canup, R.M., W.R. Ward, and A.G.W. Cameron. 2001. A Scaling Relationship for Satellite-Forming Impacts. Icarus 150(2): 288-296. https://doi.org/10.1006/icar.2000.6581.

Catling, D.C., and K.J. Zahnle. 2020. The archean atmosphere. Science Advances. https://doi.org/10.1126/sciadv.aax1420.

Chapman, G.A. 1997. Solar luminosity, 1-748. Dordrecht: Springer. https://doi.org/10.1007/1-4020-4520-4_374.

Charnay, B., E.T. Wolf, B. Marty, and F. Forget. (2020). Is the faint young Sun problem for Earth solved? arXiv:2006.06265

Chaussidon, M., and M. Gounelle. 2007. Short-lived radioactive nuclides in meteorites and early solar system processes. Comptes Rendus Geoscience 339(14): 872-884. https://doi.org/10.1016/j. crte.2007.09.005 (formation du système solaire: approche cosmochimique dans le conteste astrophysique).

Darwin, G.H. 1879. On the precession of a viscous spheroid and on the remote history of the Earth. Philosophical Transactions of the Royal Society 170: 447-530 (repr. Scientific Papers, Cambridge, Vol. II, 1908).

Darwin, G.H. 1880. On the Secular Changes in the Elements of the Orbit of a Satellite Revolving about a Tidally Distorted Planet. Royal Society of London Philosophical Transactions Series I 171: 713-891.
Davies, J.H., and D.R. Davies. 2010. Earth's surface heat flux. Solid Earth 1(1): 5-24. https://doi.org/10.5194/se-1-5-2010.

Duda, J.P., M.J. van Kranendonk, V. Thiel, D. Ionescu, H. Strauss, N. Schäfer, and J. Reitner. 2016. A rare glimpse of Paleoarchean life: Geobiology of an exceptionally preserved microbial mat facies from the $3.4 \mathrm{Ga}$ Strelley Pool Formation, Western Australia. PLoS One 11(1): 1-18. https://doi.org/10.1371/journal.pone.0147629.

Duda, J.P., V. Thiel, T. Bauersachs, H. Mißbach, M. Reinhardt, N. Schäfer, M.J. Van Kranendonk, and J. Reitner. 2018. Ideas and perspectives: hydrothermally driven redistribution and sequestration of early archaean biomass - the "hydrothermal pump hypothesis', Biogeosciences 15(5): 1535-1548. https://doi.org/10.5194/ bg-15-1535-2018.

Efroimsky, M., and V.V. Makarov. 2013. Tidal Friction and Tidal Lagging. Applicability Limitations of a Popular Formula for the Tidal Torque. The Astrophysical Journal 764(1): 26. https://doi.org/10. 1088/0004-637X/764/1/26. arXiv:1209.1615.

Emden, R. 1913. Über Strahlungsgleichgewicht und atmosphärische Strahlung. Ein Beitrag zur Theorie der oberen Inversion. Sitzungsberichte der mathematisch-physikalischen Klasse der Bayerischen Akademie der Wissenschaften München 1: 55-142.

Ferraz-Mello, S., A. Rodríguez, and H. Hussmann. 2008. Tidal friction in close-in satellites and exoplanets: The Darwin theory re-visited. Celestial Mechanics and Dynamical Astronomy 101: 171-201. https://doi.org/10.1007/s10569-008-9133-x.

Feulner, G. 2012. The faint young Sun problem. Reviews of Geophysics 50(2): RG2006. https://doi.org/10.1029/2011RG000375.

Flament, N., N. Coltice, and P.F. Rey. 2008. A case for late-archaean continental emergence from thermal evolution models and hypsometry. Earth and Planetary Science Letters 275(3): 326-336. https://doi.org/10.1016/j.epsl.2008.08.029.

Gaidos, E., B. Deschenes, L. Dundon, K. Fagan, L. Menviel-Hessler, N. Moskovitz, and M. Workman. 2005. Beyond the Principle of Plentitude: A Review of Terrestrial Planet Habitability. Astrobiology 5: 100-126. https://doi.org/10.1089/ast.2005.5.100.

Goldblatt, C., and K.J. Zahnle. 2011. Clouds and the faint young sun paradox. Climate of the Past 7(1): 203-220. https://doi.org/10. 5194/cp-7-203-2011.

Goldreich, P., and S. Soter. 1966. Q in the Solar System. Icarus 5(1): 375-389. https://doi.org/10.1016/0019-1035(66)90051-0.

Greenberg, R. 2009. Frequency Dependence of Tidal q. The Astrophysical Journal Letters 698(1): L42-L45. https://doi.org/10. 1088/0004-637X/698/1/L42.

Grotzinger, J. 2007. Understanding Earth. New York: W.H. Freeman.

Haqq-Misra, J.D., S.D. Domagal-Goldman, P.J. Kasting, and J.F. Kasting. 2008. A Revised, Hazy Methane Greenhouse for the Archean Earth. Astrobiology 8(6): 1127-1137. https://doi.org/ 10.1089/ast.2007.0197.

Heller, R., J. Leconte, and R. Barnes. 2011. Tidal obliquity evolution of potentially habitable planets. Astronomy \& Astrophysics 528: A27. https://doi.org/10.1051/0004-6361/201015809.

Henning, W.G., and T. Hurford. 2014. Tidal Heating in Multilayered Terrestrial Exoplanets. The Astrophysical Journal 789(1): 30. https://doi.org/10.1088/0004-637X/789/1/30.

Henning, W.G., R.J. O'Connell, and D.D. Sasselov. 2009. Tidally Heated Terrestrial Exoplanets: Viscoelastic Response Models. The Astrophysical Journal 707: 1000-1015. https://doi.org/10. 1088/0004-637X/707/2/1000.

Herzberg, C., K. Condie, and J. Korenaga. 2010. Thermal history of the earth and its petrological expression. Earth and Planetary Science Letters 292(1): 79-88. https://doi.org/10.1016/j.eps1. 2010.01.022.

Hickman, A.H. 1977. New and revised definitions of rock units in the Warrawoona Group, Pilbara Block. Geological Survey of Western Australia, Annual Report 1976: 58. 
Hickman-Lewis, K., B. Cavalazzi, F. Foucher, and F. Westall. 2018. Most ancient evidence for life in the Barberton greenstone belt: Microbial mats and biofabrics of the $\sim 3.47 \mathrm{Ga}$ Middle Marker horizon. Precambrian Research 312: 45-67.

Homann, M. 2019. Earliest life on earth: Evidence from the Barberton Greenstone Belt, South Africa. Earth-Science Reviews 196: 102888.

Kasting, J.F. 1982. Stability of ammonia in the primitive terrestrial atmosphere. Journal of Geophysical Research 87(C4): 30913098. https://doi.org/10.1029/JC087iC04p03091.

Kasting, J.F. 1987. Theoretical constraints on oxygen and carbon dioxide concentrations in the Precambrian atmosphere. Precambrian Research 34(3): 205-229. https://doi.org/10.1016/0301-9268(87) 90001-5.

Kasting, J.F., and J.L. Siefert. 2002. Life and the Evolution of Earth's Atmosphere. Science 296(5570): 1066-1068. https://doi.org/10. 1126/science.1071184.

Kasting, J.F., O.B. Toon, and J.B. Pollack. 1988. How climate evolved on the terrestrial planets. Scientific American 258: 90-97. https:// doi.org/10.1038/scientificamerican0288-90.

Kepler, J., C. Ptolemaeus, and R. Fludd. 1619. Harmonices mvndi libri v. qvorvm primus geometricvs, de figurarum regularium, quae proportiones harmonicas constituunt, ortu \& demonstrationibus, secundus architectonicvs, SEU EX geometria figvrata, de figurarum regularium congruentia in plano vel solido: tertius proprie harmonicvs, de proportionum harmonicarum ortu EX figuris.

Knauth, L.P. 2005. Temperature and salinity history of the Precambrian ocean: implications for the course of microbial evolution. Palaeogeography, Palaeoclimatology, Palaeoecology 219(1): 53-69. https://doi.org/10.1016/j.palaeo.2004.10.014.

Kranendonk, M.J. van. 2011. Morphology as an indictor of biogenicity for 3.5-3.2 Ga fossil stromatolites from the Pilbara Craton, Western Australia. In: Advances in Stromatolite Geobiology, eds. J. Reitner, N.-V. Quéric, G. Arp, p 32. Berlin: Springer Berlin Heidelberg. https://doi.org/10.1007/978-3-642-10415-2_32

Kranendonk, M.J. van, P. Philippot, K. Lepot, S. Bodorkos, and F. Pirajno. 2008. Geological setting of earth's oldest fossils in the ca. 3.5 Ga dresser formation, Pilbara Craton, Western Australia. Precambrian Research 167(1): 93-124. https://doi.org/10.1016/j. precamres.2008.07.003.

Kranendonk, M.J. van, W. Altermann, B.L. Beard, P.F. Hoffman, C.M. Johnson, J.F. Kasting, V.A. Melezhik, A.P. Nutman, D. Papineau, and F. Pirajno. 2012. Char 16-a chronostratigraphic division of the Precambrian: Possibilities and challenges. In The Geologic Time Scale, eds. F.M. Gradstein, J.G. Ogg, M.D. Schmitz, and G.M. Ogg, 299-392. Boston: Elsevier.

Kuhn, W.R., and S.K. Atreya. 1979. Ammonia photolysis and the greenhouse effect in the primordial atmosphere of the earth. Icarus 37(1): 207-213. https://doi.org/10.1016/0019-1035(79) 90126-X.

Kuhn, W.R., and J.F. Kasting. 1983. Effects of increased CO2 concentrations on surface temperature of the early earth. Nature 301: 53-55. https://doi.org/10.1038/301053a0.

Lg, Liu. 2004. The inception of the oceans and co2-atmosphere in the early history of the earth. Earth and Planetary Science Letters 227(3-4): 179-184. https://doi.org/10.1016/j.epsl.2004.09.006.

Love, A.E.H. 1909. The Yielding of the Earth to Disturbing Forces. Proceedings of the Royal Society of London Series A 82(551): 73-88. https://doi.org/10.1098/rspa.1909.0008.

Lowe, D.R. 1980. Stromatolites 3,400-myr old from the Archean of Western Australia. Nature 284(5755): 441-443. https://doi.org/ 10.1038/284441a0.

MacDonald, G.J.F. 1964. Tidal friction. Reviews of Geophysics 2(3): 467-541. https://doi.org/10.1029/RG002i003p00467.

Maltese, A., and K. Mezger. 2020. The pb isotope evolution of bulk silicate earth: Constraints from its accretion and early differentiation history. Geochimica et Cosmochimica Acta 271: 179-193. https:// doi.org/10.1016/j.gca.2019.12.021.

Meyer, J., and J. Wisdom. 2007. Tidal heating in Enceladus. Icarus 188(2): 535-539. https://doi.org/10.1016/j.icarus.2007.03.001.

Miller, S.L., and H.C. Urey. 1959. Organic Compound Synthesis on the Primitive Earth. Science 130(3370): 245-251. https://doi.org/ 10.1126/science.130.3370.245.

Mojzsis, S.J., T.M. Harrison, and R. Pidgeon. 2001. Oxygen-isotope evidence from ancient zircons for liquid water at the earth's surface 4,300 myr ago. Nature 409: 178. https://doi.org/10.1038/ 35051557.

Nesbitt, R., B.M. Jahn, and A. Purvis. 1982. Komatiites: An early Precambrian phenomenon. Journal of Volcanology and Geothermal Research 14(1): 31-45. https://doi.org/10.1016/0377-0273(82) 90041-5.

Nisbet, E.G., and N.H. Sleep. 2001. The habitat and nature of early life. Nature 409(6823): 1083-1091. https://doi.org/10.1038/35059210.

Pavlov, A.A., J.F. Kasting, L.L. Brown, K.A. Rages, and R. Freedman. 2000. Greenhouse warming by $\mathrm{CH}_{4}$ in the atmosphere of early Earth. Journal of Geophysical Research 105(E5): 11981-11990. https://doi.org/10.1029/1999JE001134.

Peale, S.J., P. Cassen, and R.T. Reynolds. 1979. Melting of Io by Tidal Dissipation. Science 203(4383): 892-894. https://doi.org/10.1126/ science.203.4383.892.

Planck, M. 1901. Ueber das Gesetz der Energieverteilung im Normalspectrum. Annalen der Physik 309(3): 553-563. https://doi.org/ 10.1002/andp.19013090310.

Porco, C.C., P. Helfenstein, P.C. Thomas, A.P. Ingersoll, J. Wisdom, R. West, G. Neukum, T. Denk, R. Wagner, T. Roatsch, S. Kieffer, E. Turtle, A. McEwen, T.V. Johnson, J. Rathbun, J. Veverka, D. Wilson, J. Perry, J. Spitale, A. Brahic, J.A. Burns, A.D. Del Genio, L. Dones, C.D. Murray, and S. Squyres. 2006. Cassini Observes the Active South Pole of Enceladus. Science 311(5766): 1393-1401. https://doi.org/10.1126/science.1123013.

Ribas, I., E.F. Guinan, M. Güdel, and M. Audard. 2005. Evolution of the Solar Activity over Time and Effects on Planetary Atmospheres. I. High-Energy Irradiances (1-1700 ̊). The Astrophysical Journal 622(1): 680-694. https://doi.org/10.1086/427977.

Rosing, M.T. 1999. 13c-depleted carbon microparticles in $>3700$ -ma sea-floor sedimentary rocks from west Greenland. Science 283(5402): 674-676. https://doi.org/10.1126/science.283.5402. 674.

Sagan, C. 1969. Gray and Nongray Planetary Atmospheres. Structure, Convective Instability, and Greenhouse Effect. Icarus 10(2): 290_ 300. https://doi.org/10.1016/0019-1035(69)90030-X.

Sagan, C., and C. Chyba. 1997. The early faint sun paradox: Organic shielding of ultraviolet-labile greenhouse gases. Science 276: 1217-1221. https://doi.org/10.1126/science.276.5316.1217.

Sagan, C., and G. Mullen. 1972. Earth and mars: Evolution of atmospheres and surface temperatures. Science 177(4043): 52-56. https://doi.org/10.1126/science.177.4043.52.

Schidlowski, M. 1988. A 3,800-million-year isotopic record of life from carbon in sedimentary rocks. Nature 333(6171): 313-318.

Selsis, F., J.F. Kasting, B. Levrard, J. Paillet, I. Ribas, and X. Delfosse. 2007. Habitable planets around the star Gliese 581? Astronomy \& Astrophysics 476(3): 1373-1387. https://doi.org/ 10.1051/0004-6361:20078091.

Sengupta, S., S.T. Peters, J. Reitner, J.P. Duda, and A. Pack. 2020. Triple oxygen isotopes of cherts through time. Chemical Geology 554: 119789. https://doi.org/10.1016/j.chemgeo.2020. 119789.

Shapiro, A.V., A.I. Shapiro, L. Gizon, N.A. Krivova, and S.K. Solanki. 2020. Solar-cycle irradiance variations over the last four billion years. Astronomy \& Astrophysics 636: A83. https://doi.org/10. 1051/0004-6361/201937128. 
Shimizu, I. 2015. Past and present experiments of geoneutrinos. Physics Procedia 61: 355-358. https://doi.org/10.1016/j.phpro.2014. 12.075 .

Smith, B.A., L.A. Soderblom, T.V. Johnson, A.P. Ingersoll, S.A. Collins, E.M. Shoemaker, G.E. Hunt, H. Masursky, M.H. Carr, M.E. Davies, I. Cook, F. Allan, J. Boyce, G.E. Danielson, T. Owen, C. Sagan, R.F. Beebe, J. Veverka, R.G. Strom, J.F. McCauley, D. Morrison, G.A. Briggs, and V.E. Suomi. 1979. The Jupiter System Through the Eyes of Voyager 1. Science 204(4396): 951-957. https://doi.org/10.1126/science.204.4396.951.

Solanki, S.K., N.A. Krivova, and J.D. Haigh. 2013. Solar Irradiance Variability and Climate. Annual Review of Astronomy \& Astrophysics 51(1): 311-351. https://doi.org/10.1146/annur ev-astro-082812-141007.

Spencer, J.R., K.L. Jessup, M.A. McGrath, G.E. Ballester, and R. Yelle. 2000. Discovery of Gaseous $S_{2}$ in Io's Pele Plume. Science 288(5469): 1208-1210. https://doi.org/10.1126/science.288. 5469.1208 .

Spohn, T. 1991. Mantle differentiation and thermal evolution of Mars, Mercury, and Venus. Icarus 90: 222-236. https://doi.org/10.1016/ 0019-1035(91)90103-Z.

Stefan, J. 1879. Über die Beziehung zwischen der Wärmestrahlung und der Temperatur. Sitzungsberichte der mathematisch-naturwissenschaftlichen Classe der kaiserlichen Akademie der Wissenschaften in Wien 79: 391-428

Terez, E.I., and G.A. Terez. 2003. A method to determine atmospheric optical depth using observations of direct solar radiation. Journal of Geophysical Research: Atmospheres. https://doi.org/10.1029/ 2003JD003829.

Turcotte, D.L., and J.C. Pflugrath. 1985. Thermal structure of the accreting earth. Journal of Geophysical Research: Solid Earth 90(S02): C541-C544. https://doi.org/10.1029/JB090iS02p0C541.

Urey, H.C. 1955. The cosmic abundances of potassium, uranium, and thorium and the heat balances of the earth, the moon, and mars. Proceedings of the National Academy of Sciences 41(3): 127-144. https://doi.org/10.1073/pnas.41.3.127.

Valley, J.W., A.J. Cavosie, T. Ushikubo, D.A. Reinhard, D.F. Lawrence, D.J. Larson, P.H. Clifton, T.F. Kelly, S.A. Wilde, D.E. Moser, and M.J. Spicuzza. 2014. Hadean age for a post-magma-ocean zircon confirmed by atom-probe tomography. Nature Geoscience 7(3): 219-223. https://doi.org/10.1038/ngeo2075.
Walker, J.C.G. 1983. Possible limits on the composition of the Archaean ocean. Nature 302(5908): 518-520. https://doi.org/10. 1038/302518a0.

Walker, J.C.G., and K.J. Zahnle. 1986. Lunar nodal tide and distance to the Moon during the Precambrian. Nature 320(6063): 600-602. https://doi.org/10.1038/320600a0.

Walter, M.R., R. Buick, and J.S.R. Dunlop. 1980. Stromatolites 34003500 myr old from the north pole area, Western Australia. Nature 284(5755): 443-445. https://doi.org/10.1038/284443a0.

Webb, D.J. 1980. Tides and tidal friction in a hemispherical ocean centred at the equator. Geophysical Journal 61: 573-600. https:// doi.org/10.1111/j.1365-246X.1980.tb04833.x.

Webb, D.J. 1982. Tides and the evolution of the earth-moon system. Geophysical Journal 70: 261-271. https://doi.org/10.1111/j.1365246X.1982.tb06404.X.

Wei, P.S., H.H. Chiu, Y.C. Hsieh, D.L. Yen, C. Lee, Y.C. Tsai, and T.C. Ting. 2019. Absorption coefficient of water vapor across atmospheric troposphere layer. Heliyon 5(1): e01145. https://doi.org/10. 1016/j.heliyon.2019.e01145.

Whitmire, D.P., L.R. Doyle, R.T. Reynolds, and J.J. Matese. 1995. A slightly more massive young Sun as an explanation for warm temperatures on early Mars. Journal of Geophysical Research 100(E3): 5457-5464. https://doi.org/10.1029/94JE03080.

Wilde, S.A., J.W. Valley, W.H. Peck, and C.M. Graham. 2001. Evidence from detrital zircons for the existence of continental crust and oceans on the earth 4.4 gyr ago. Nature 409: 175. https://doi. org/10.1038/35051550.

Young, G.M., V.V. Brunn, D.J.C. Gold, and W.E.L. Minter. 1998. Earth's oldest reported glaciation: Physical and chemical evidence from the archean mozaan group $(\sim 2.9 \mathrm{Ga})$ of South Africa. The Journal of Geology 106(5): 523-538.

Zahnle, K., N. Arndt, C. Cockell, A. Halliday, E. Nisbet, F. Selsis, and N.H. Sleep. 2007. Emergence of a Habitable Planet. Space Science Reviews 129: 35-78. https://doi.org/10.1007/s11214-007-9225-z.

Zahnle, K.J., R. Lupu, A. Dobrovolskis, and N.H. Sleep. 2015. The tethered Moon. Earth and Planetary Science Letters 427: 74-82. https://doi.org/10.1016/j.eps1.2015.06.058. arXiv:1508.01467.

Zschau, J. 1978. Tidal Friction in the Solid Earth: Loading Tides Versus Body Tides. In Tidal Friction and the Earth's Rotation, eds. P. Brosche, and J. Suendermann, 62-94. Berlin / Heidelberg: Springer. 